\title{
IRRITANTCY POTENTIAL AND SUB ACUTE DERMAL TOXICITY STUDY OF PISTACIA LENTISCUS FATTY OIL AS A TOPICAL TRADITIONAL REMEDY.
}

\section{Zouhir DJERROU ${ }^{\mathrm{a}}$, Hdria DJAALAB $^{\mathrm{a}}$, Foulla RIACHI ${ }^{\mathrm{a}}$, Mennouba SERAKTA ${ }^{\mathrm{a}}$, Aziez CHETTOUM $^{\mathrm{b}}$, Zineb MAAMERI ${ }^{\mathrm{a}}$, Badaoui BOUTOBZA ${ }^{\mathrm{c}}$, Youcef HAMDI-PACHA ${ }^{\mathrm{a}, \mathrm{d}}$.}

\author{
${ }^{a}$ Laboratoire de Pharmacologie Toxicologie, Département des Sciences Vétérinaires, Université \\ Mentouri de Constantine, Algérie. \\ ${ }^{B}$ Laboratoire de Neuro Physiologie, Université Badji Mokhtar Annaba, Algérie. \\ ${ }^{\mathrm{C}}$ Etablissement Public hospitalier de Tamalous Skikda, Algérie. \\ ${ }^{\mathrm{d}}$ Directeur de l'école Nationale Vétérinaire Supérieure, El Harrach, Algérie. \\ *E-mail: Zouhir21265@yahoo.frr
}

\begin{abstract}
The current study was undertaken to assess safety of Pistacia lentiscus fruits fatty oil (PLFO) as a topical traditional remedy. A primary skin and eye irritation tests were conducted with New Zealand white rabbits to determine the potential for PLFO to produce irritation from a single application. In addition, a sub acute dermal toxicity study was performed on 18 NZW rabbits to evaluate possible adverse effect following application of PLFO for 28 days. Based on the results of the current study, PLFO is classified as slightly irritating to the skin and the eye of rabbits (Primary Irritation Index $($ P.I.I. $)=1.037$; Ocular Irritation Index (O.I.I.) $=5.33$ at $1 \mathrm{~h}$ ). In the sub-acute toxicity test, PLFO produced neither mortality nor significant differences in the body and organ weights between control group and treated rabbits. However, a reversible irritant contact dermatitis was observed in the treated areas from the end of the second week of application until the end of experiment. This local phenomenon was accompanied by a significant skin thickening $(\mathrm{P} \leq 0.01)$ since the $12^{\text {th }}$ day (ANOVA, $\mathrm{F}=11,07143, \mathrm{P}=0,00765)$ which is confirmed with an inflammatory granuloma in histological study. Haematological analysis and blood chemistry values of the 2 groups showed no significant differences in any of the parameters examined. In summary, PLFO is minimally irritating to the eye and skin after a single exposure, but it may cause irritant contact dermatitis and a reversible thickening of skin after prolonged use.
\end{abstract}

Key words: Pistacia lentiscus, fatty oil, skin, eye, dermatitis, irritation, toxicity.

\section{Introduction}

Pistacia lentiscus L. (Mastic) is an aromatic member of the Anacardiaceae family, largely distributed in the flora of Mediterranean area, which is characterized by nutrient and water scarcity and long term exposures to extensive solar radiation and high temperatures (Margaris, 1981). This dioecious species can reach $3 \mathrm{~m}$ in height (Bonnier and Douin, 1990) and grows wild also in Algeria, Turkey, Morocco, France, Spain, Italy and Greece (Tingshuang et al., 2008).

The fruit, galls, resin and leaves of the $P$. lentiscus have a long tradition in folk medicine dating from the time of the ancient Egyptians and Greeks (Palevitch and Yaniv, 2000; Pellecuer et al., 1980). Serpico and White (1998) reported that there is some evidence of the use of pistacia resin in mummification, at least as early as the Third Intermediate Period. The aerial part has traditionally been used as a stimulant, for its diuretic properties, and to treat hypertension, coughs, sore throats, eczema, stomach aches, kidney stones and jaundice (Bentley and Trimen, 1980; Palevitch and Yaniv, 2000). Mastic gum is a natural resin that is excreted from the trunk and branches of the mastic bush (Pistacia lentiscus var. Chia). This excretion is produced by incising the bark with a sharp instrument (Dabos et al., 2010). It has been used by traditional healers for the relief of upper abdominal discomfort, stomach aches, dyspepsia and peptic ulcer (Al-Habbal et al., 1984).

In the past, $P$. lentiscus L. oil is used in several industrial applications such as perfumery, food and pharmaceutical (Calabro and Curro, 1974) and it has been re-evaluated these last years as a flavouring in alcoholic beverages and chewing gum (Fernandez et al., 2000). Several studies have also reported that essential oil from aerial parts of P. lentiscus L. possesses appreciable biological properties such as antioxidant, antiinflammatory, antimicrobial (Benhammou et al., 2008), antifungal (Duru et al., 2003; Kordali et al., 2003) and antiatherogenic activities (Dedoussis et al., 2004).

The chemical composition of the essential oil of $P$. lentiscus have been investigated by several researchers (Amhamdi et al. 2009, Barra et al. 2007, Castola et al. 2000, Duru et al. 2003, Zrira et al. 2003, Mecherara-Idjeri et al. 2008, Kivçak et al.2004, Vidrich et al.2004, and Benyoucef et al. 2005).

However, little is known about the fatty oil extracted from $P$. lentiscus fruits. This edible oil is used traditionally by the Tunisian population in their daily diet in salads and pastries. It also serves as a condiment in the North West of Tunisia and is used in the treatment of scabies, rheumatism and in the manufacture of anti-diarrhoea pills (Le Floc'h and Nabli, 1983; Trabelsi et al., 2012). In Eastern Algeria, some families used this fatty oil traditionally to treat respiratory disorders, stomach aches, dermal burns, lombalgies and varicose veins. We have proved scientifically, in a previous study, that this oil stimulates the cicatrizing process in rabbit model (Djerrou et al., 2010). When applied daily for a six consecutive weeks via rectal route in New Zealand rabbits, the oil was proven to be safe with no adverse effects on liver and kidney functions (Djerrou et al. , 
2011). A study of Tounes et al. (2008) has demonstrated the possibility of this oil to help partially in the protection against mercury intoxication.

We stated that there are a few reports published about the fatty acids composition (Charef et al., 2008; Trabelsi et al., 2012; Ucciani, 1995) and sterols (Trabelsi et al., 2012) of this oil. Nowadays, the production and the utilization of this oil for therapeutic purposes is increasing year after year. Hence, the present study was undertaken to determine the ability of PLFO to irritate the skin and the eye following an acute exposure and to investigate possible adverse effects after repeated dermal application of this oil for 4 weeks.

\section{Materials and Methods \\ Extraction of Pistacia lentiscus fatty oil}

Pistacia lentiscus fruits (Voucher Specimen: PL-1210ZD) were collected from Tamalous region located in Skikda (East of Algeria) in December 2010. They were air dried in a shady place for 10 days, and then oil was extracted by traditional manner in different steps. First the fruits were ground into a paste, which was then mixed for 30 minutes. After grinding the paste, cold water was added and well mixed. Finally the fatty oil was separated from the liquids by decantation and was stored away from light and moisture until use.

\section{Animals and housing conditions}

Healthy male New-Zealand White rabbits (NZW) were purchased from a local supplier (Hama Bouziane, Constantine, Algeria) and used for these studies. Animals were kept in individual standard cages in standardized environment condition with an ambient temperature of $22 \pm 2^{\circ} \mathrm{C}$ and a $12 \mathrm{~h}$ light-dark cycle. Food and water were provided ad libitum. Animals were acclimated for laboratory conditions for a period of 7 days prior to initiation of the different tests. All the experimental procedures adopted were approved by Faculty of science, University of Constantine, Algeria.

\section{Primary Dermal Irritation Study (Limit Test)}

The purpose of this study is to assess the skin irritation potential of Pistacia lentiscus fatty oil from a single topical application for a four hour period. We have utilized the dermal irritation test method according to the OECD Testing Guideline $\mathrm{n}^{\circ} 404$ adopted April 24, 2002. Six male New Zealand white rabbits weighing between 2.7-3.2 kg were used for the present study and each animal served as its own control. On day 0 of the test period, the rabbits were shaved using electric shaver on the trunk and lateral areas (about $10 \%$ of the body surface area for application of the test substance). The left side (about $6 \mathrm{~cm}^{2}$ ) served as a test site, while the right site served as a control site. The rabbits were caged individually and left undisturbed for $24 \mathrm{~h}$. On day 1 of the test period, the oil was applied, at the dose of $0.5 \mathrm{ml} / \mathrm{site}$, to intact and abraded skin and was covered with gauze patches which were secured with adhesive tape. In addition to applying the patches of intact skin, patches are applied to areas of skin which have been abraded by scoring through the Stratum corneum, but not sufficiently to cause bleeding (Lansdown, 1972). The rabbits were then returned to their cages. After 24 hrs the patches were removed and the skin response was scored from erythema and oedema for each rabbit at 1 and $24 \mathrm{hrs}$ after the removal. Dermal irritation was scored and recorded according to the Draize scoring system (Table 1) (Draise et al., 1944). The average of the combined scores given for the areas of intact and abraded skin was referred to as the Primary Irritation Index (Lansdown, 1972).

Table 1: Draize scoring system*

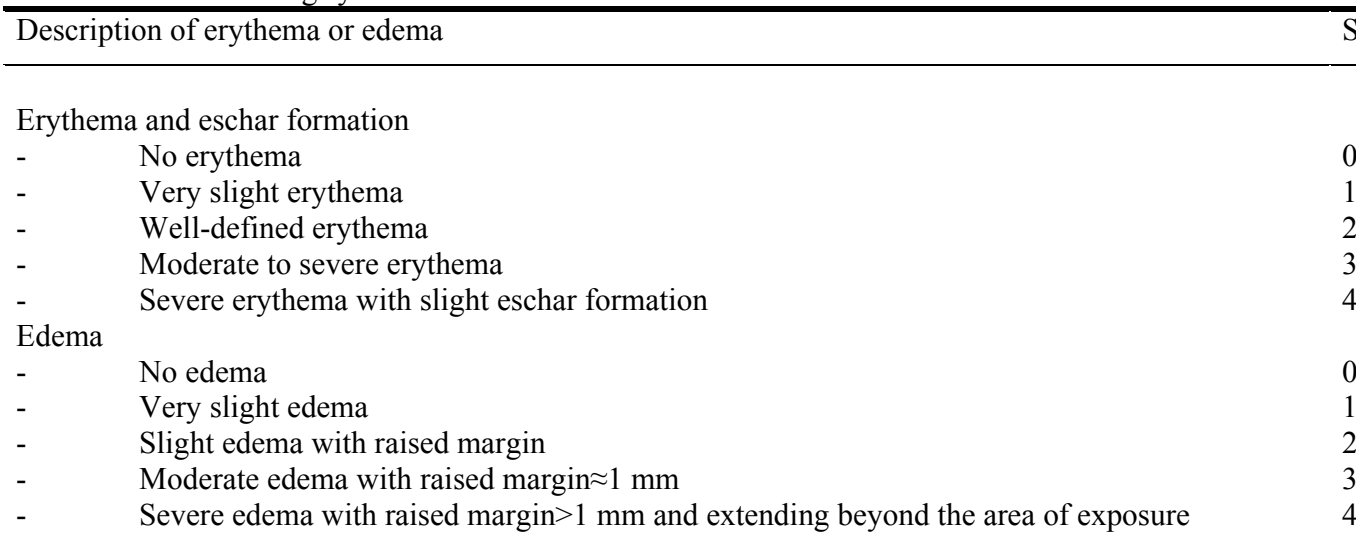

\footnotetext{
Note: The interpretation of scoring $;<2=$ slight irritation, $2-5=$ moderately irritation and $>5=$ severely irritation

${ }^{*}$ Draize et al. (1944).
} 
The objective of this study was to determine the potential for PLFO to produce irritation from a single instillation via the ocular route according to OECD guideline No 405 for the evaluation of chemicals, adopted April 24, 2002. The test was performed on $3 \mathrm{New}$ Zealand male, white rabbits weighing from 2.5 to $2.9 \mathrm{~kg}$. Both eyes of each animal likely to participate in the trial were reviewed within 24 hours before the start of the test in order to remove the animals showing signs of eye irritation, ocular defects or damage of the cornea. The test consists of a single application of $0.1 \mathrm{ml}$ of PLFO in the left conjunctival sack of each rabbit. The upper and lower lids were gently held together for about $1 \mathrm{~s}$ before releasing to minimize loss of the test oil (Zhu et al., 2009). The non-treated right eyes were served as controls. The test was conducted in two stages, as recommended by the OECD (2002), instillation was first performed on a single animal (Initial test), and has been generalized to the rest of rabbits (Confirmatory test) confirmation of the initial test shows no corrosive effect.

The animals were observed at $1 \mathrm{~h}, 24,48,72 \mathrm{hrs}$ and 7 days after instillation. The eyes of rabbits were observed and evaluated according to the method of Draize et al. (1944). After observation using a slit lamp, one drop of $2 \%$ fluorescein sodium (in water) was applied to the eyes of the rabbits, and after a few seconds, the eyes were washed with water and

Table 2: Scoring criteria for ocular irritation in primary eye irritation study ${ }^{*}$.

\begin{tabular}{ll}
\hline I & Cornea \\
(A) Area of cornea involved & 0 \\
No ulceration or opacity & 1 \\
$>0 \%, \leq 25 \%$ & 2 \\
$>25 \%, \leq 50 \%$ & 3 \\
$>50 \%, \leq 75 \%$ & 4 \\
$>75 \%, \leq 100 \%$ & Maximum total=12 \\
Score $=\mathrm{A} \times 3$ & 0 \\
Iris $\quad$ Values & 1 \\
(A) & 2 \\
Normal & Maximum total=6 \\
Markedly deepened rugae, congestion, swelling, circumcorneal injection (any or all these or & 1 \\
combination thereof), iris still reacting to light ( sluggish reaction is positive) & \\
No reaction to light, haemorrhage, gross destruction (any or all of these) & 0 \\
Score $=$ A $\times 3$ & 1 \\
Conjunctivae & 2 \\
(A) Redness (refers to palpebral and bulbar conjunctivae excluding cornea and iris) & 3 \\
Blood vessels normal & Maximum total=9 \\
Some blood vessels definitely hyperaemic(injected above) normal & Maximum total score possible =27
\end{tabular}

"Draize et al. (1944).

Note: Classification of eye irritation scores: $0.0-0.5=$ non; $0.6-2.5=$ practically non; $2.6-15.0=$ minimally; $15.1-25.0=$ mildly; $25.1-50.0=$ moderately; $50.1-80.0=$ severely; $80.1-100.0=$ extremely; $100.1-110=$ maximally (Kay and Calandra, 1962).

the surface of the cornea was observed (Takahashi et al., 1999). The animals were also observed for signs of gross toxicity and behavioral changes at least once daily during the test period. The average score for all rabbits at each scoring period was calculated, and the time interval with the highest mean score (Maximum Mean Total Score-MMTS) for all rabbits was used to further classify the tested oil by the system of Kay and Calandra (1962).

\section{Repeated dose dermal toxicity: 21/28 days (Test-limit)}

The study was conducted according to the recommendations of the OECD guideline No 410 for Testing of Chemicals, adopted May 12, 1981. The test was performed on $18 \mathrm{New}$ Zealand (male, white, Initial weight 2.25 to $2.4 \mathrm{~kg}$, age 3 months) rabbits; 6 for the control group and the rest for the tested group. 6 animals from the tested group were considered as satellite group. PLFO was applied topically, at the dose of $1 \mathrm{ml} / \mathrm{Kg} \mathrm{BW} /$ site of about $6 \mathrm{~cm}$ square once a day for a period of 28 days for tested animals (MHLW, 2002). Body weight measurements were taken every week. Fur was clipped, carefully to ovoid abrading the skin, from the dorsal area of the trunk $24 \mathrm{~h}$ prior to the test and repeated at a weekly interval (EPA, 1998). The rabbits were treated with PLFO once daily. Signs of toxicity (described above) were recorded daily, including onset, degree and duration of toxicity. The treated areas were observed for erythema, edema, skin thickening, cracks, scabs and hair growth. At the end of the experiment, the animals were fasted overnight, and for haematologic and biochemical analysis, blood samples from the marginal ear vein were collected into tubes containing heparin as an anticoagulant. All rabbits of control group and one half of tested animals were killed and the rest (satellite group) were maintained and observed for 14 additional days to test reversibility of lesions.

\section{Haematological Study}


Haematological parameters performed were haematocrit $(\mathrm{Ht})$, haemoglobin concentration $(\mathrm{Hb})$, Mean Corpuscular Volume (MCV), Mean Corpuscular Hemoglobin Concentration (MCHC), WBC count, lymphocytes, monocytes, granulocytes and platelet count.

\section{Biochemical assays}

Blood samples were centrifuged at $3000 \mathrm{rpm}$ for $5 \mathrm{~min}$ and the plasma was separated. Selected blood parameters were estimated using an automatic analyzer (Architect CI 8200) in the Hospital Centre of Constantine, and included aspartate amino transferase (AST), alanine amino transferase (ALT), alkaline phosphokinase (Alk-P), blood creatinine, urea, fasting glucose (GLU), total serum protein (TP), albumin (ALB), total cholesterol and triglycerides.

\section{Pathological Anatomy and Histology}

In this study, all animals treated (except for satellite group) or untreated were subjected to a full gross necropsy which included: the examination of the external surface of the body, all orifices, cavities (cranial, thoracic and abdominal) and their contents. The liver, kidneys, adrenals, testes, lungs, heart, spleen, bladder, cerebrum and cerebellum were weighed wet, as soon as possible after dissection to avoid drying. Normal skin and treated skin, liver and kidneys were conserved in formaldehyde (10\%) for histological examination.

\section{Statistical Analysis}

The irritation data are presented as visual scores based on Draize method of erythema and edema, and the Primary Irritation Index (IPI) was calculated. The data obtained from measurements of body weight and the organs were expressed as mean \pm SD and were analyzed by One-way ANOVA. The haematological and biochemical parameters were expressed as median \pm IQR (Interquartile range) and were analyzed by Mann-Whitney U test. All statistical tests were processed by statistical software (SPSS 10.0 program). The significance level was set at $5 \%$.

\section{Results}

\section{Primary Dermal Irritation Study}

There was no clinically observable systematic toxicity in any of the tested rabbits. Table 3 shows visual Draize scores for erythema and edema $24 \mathrm{~h}$ and $72 \mathrm{hrs}$ after removal of the gauze patches. No edema was observed in any tested rabbits during the test; however, a reaction of erythema was recorded in the treated areas of animals. The PII correspondent was calculated to be 1.037 . Noting that no irritation on the skin of the control area was observed throughout the entire testing period. In the light of the above observations, we can classify PLFO as slightly irritant of the skin of rabbit.

Table 3: The score of erythema and edema of rabbits treated with PLFO at 24 and 72 hours.

\begin{tabular}{|c|c|c|c|c|c|}
\hline \multirow[t]{2}{*}{ Hrs } & \multirow[t]{2}{*}{ Rabbit $n^{\circ}$. } & \multicolumn{2}{|c|}{ Intact } & \multicolumn{2}{|c|}{ Abraded } \\
\hline & & $\mathrm{Er}^{\mathrm{a}}$ & $\mathrm{Ed}^{\mathrm{b}}$ & Er & $\mathrm{Ed}$ \\
\hline \multirow[t]{7}{*}{24} & 1 & 2 & 0 & 1 & 0 \\
\hline & 2 & 1 & 0 & 1 & 0 \\
\hline & 3 & 2 & 0 & 1 & 0 \\
\hline & 4 & 1 & 0 & 1 & 0 \\
\hline & 5 & 2 & 1 & 2 & 1 \\
\hline & 6 & 1 & 0 & 1 & 0 \\
\hline & Mean & 1.5 & 0.16 & 1.16 & 0.16 \\
\hline \multirow[t]{7}{*}{72} & 1 & 1 & 0 & 1 & 0 \\
\hline & 2 & 1 & 0 & 1 & 0 \\
\hline & 3 & 2 & 0 & 1 & 0 \\
\hline & 4 & 1 & 0 & 2 & 0 \\
\hline & 5 & 2 & 0 & 2 & 0 \\
\hline & 6 & 1 & 0 & 1 & 0 \\
\hline & Mean & 1.33 & 0.0 & 1.33 & 0.0 \\
\hline \multicolumn{2}{|c|}{ Primary Irritation Index $(\mathrm{PII})^{\mathrm{c}}$} & \multicolumn{4}{|c|}{1.037} \\
\hline \multicolumn{2}{|c|}{ Category of irritation } & \multicolumn{4}{|c|}{ Slight irritation } \\
\hline
\end{tabular}

${ }^{\mathrm{a}} \mathrm{Er}=$ Erythema, ${ }^{\mathrm{b}} \mathrm{Ed}=\mathrm{Edema},{ }^{\mathrm{c}}$ Primary Irritation Index $=\Sigma$ mean score $/$ number of animal treated.

\section{Primary Eye Irritation Study}

During the experimental period, no particular behavior was observed in the three rabbits which appeared active and healthy, apart from the eye irritation observed in treated eyes. The results obtained (Table 4) show that no corneal opacity or 
iritis was observed during the test period. All three treated eyes exhibited conjunctivitis one hour after PLFO instillation, but the overall incidence and severity of irritation decreased with time. The maximum mean total obtained at 1 hour was $16(n=3)$ with a correspondent ocular irritation index of 5.33. This index was regressed to 0.66 at 24 hours. All rabbits were free from ocular irritation at 48 hours.

Table 4: Incidence, severity and reversibility of ocular irritation in male New Zealand White rabbits after exposure to PLFO $(n=3)$.

\begin{tabular}{|c|c|c|c|c|c|}
\hline Time post-instillation(h) & Corneal opacity & Iritis & Conjunctivitis & MMT value & O.I.I \\
\hline 1 & $0 / 0 / 0$ & $0 / 0 / 0$ & $6 / 4 / 6$ & $16 / 3$ & 5.33 \\
\hline 24 & $0 / 0 / 0$ & $0 / 0 / 0$ & $0 / 2 / 0$ & $2 / 3$ & 0.66 \\
\hline 48 & $0 / 0 / 0$ & $0 / 0 / 0$ & $0 / 0 / 0$ & 0 & 0 \\
\hline 72 & $0 / 0 / 0$ & $0 / 0 / 0$ & $0 / 0 / 0$ & 0 & 0 \\
\hline 96 & $0 / 0 / 0$ & $0 / 0 / 0$ & $0 / 0 / 0$ & 0 & 0 \\
\hline 168 & $0 / 0 / 0$ & $0 / 0 / 0$ & $0 / 0 / 0$ & 0 & 0 \\
\hline
\end{tabular}

${ }^{*}$ MMT, maximum mean total, ${ }^{* *}$ O.I.I, Ocular Irritation Index.

\section{Repeated dose dermal toxicity: 21/28 days (Limit-test)}

During the entire period of experimentation, no animal showed a sign of abnormal behavior in treated or untreated group.

\section{Evolution of body weight}

The rabbits weight weekly showed that the difference between the averages of the two groups was not significant. The mean weight of the experimental group has changed from $2300 \pm 150 \mathrm{~g}$ to $2870 \pm 183 \mathrm{~g}$ at the end of the fourth week, while the mean weight for the control group ranged from $2360 \pm 70 \mathrm{~g}$ to $2920 \pm 137 \mathrm{~g}$ at the end the experimental period (Table 5). This implies that the application of P. lentiscus fatty oil topically at a dose of $1 \mathrm{ml} / \mathrm{kg}$ for 28 days did not affect the growth of rabbits.

\section{Dermatological results \\ Evolution of the general condition of the skin}

During the first fifteen days of experimentation, hair growth has been hindered, but this phenomenon was similar in both groups. Subsequently, the growth was back to normal in three rabbits of the treated group while the remaining rabbits showed a faster rate of regrowth compared with animals of the same treated group or control group. Two rabbits from the experimental group presented slight cracks and scabs in the treated areas from the 18th days of application till end of the test.

\section{Quantification of irritation}

An erythema was observed in the first week of application, edema was also observed in treated areas of two rabbits; the erythematic reaction was increasing and decreasing alternately until the end of the experiment.. Skin sensitization was observed in two rabbits, but this was quite reversible before the end of the second week following the end of experimentation (The reversibility was confirmed in the satellite group).

\section{Thickness of the skin}

Thickening of the skin was observed in four of the six treated rabbits. This persisted until the end of the experimental period (Table 5). The skin of two rabbits that showed skin sensitization reached $100 \%$ of the thickness of the untreated skin or that of control rabbits. After stopping the topical application of PLFO, the skin of animals has recovered its texture and its original volume in 12 days.

\section{Haematological analysis}

Haematological parameters recorded in Table 6 show the values belonging generally to the physiological range, both in treated animals than for controls. However, the sixth rabbit from the experimental group recorded a slight decrease of haematocrit $(28.2 \%)$, a significant decrease in platelet count $\left(60 \times 10^{3} / \mathrm{mm}^{3}\right)$ when compared with medians of its own group (PLFO) or control group. The same rabbit recorded an increase in lymphocytes $(66.9 \%)$ and monocytes (24\%), with a consequent decrease of granulocytes $(9 \%)$. Noting that the statistical study by Mann-Whitney $U$ test showed that all differences between the two groups were not significant. What it leads us to conclude that the topical application of PLFO caused no disturbance of haematological parameters. 
http://dx.doi.org/10.4314/ajtcam.v10i3.15

Table 5: Four-week repeated dermal toxicity of PLFO in New Zealand White rabbits.

\begin{tabular}{|c|c|c|c|c|c|c|}
\hline \multirow{2}{*}{$\begin{array}{l}\text { Animal group } \\
(n=6)\end{array}$} & \multirow[b]{2}{*}{ Clinical signs } & \multicolumn{5}{|c|}{ Time after administration (in days) } \\
\hline & & 1 & 7 & 12 & 19 & 28 \\
\hline \multirow{5}{*}{$\begin{array}{l}\text { Test group } \\
(1 \mathrm{ml} \text { PLFO/Kg } \\
\left.\mathrm{BW} / \text { site of } 6 \mathrm{~cm}^{2}\right)\end{array}$} & $\begin{array}{l}\text { Number of animals with } \\
\text { abnormality (Hypo activity) }\end{array}$ & 0 & 0 & 0 & 0 & 0 \\
\hline & Hair growth $(-/+/++)$ & - & - & + & ++ & ++ \\
\hline & $\begin{array}{l}\text { Skin thickening } \\
(\mathrm{mm} \pm \mathrm{SD})\end{array}$ & $2.06 \pm 0.006$ & $2.15 \pm 0.011$ & $3.1 \pm 0.572^{*}$ & $2.35 \pm 0.019^{\ddagger}$ & $2.36 \pm 0.018^{\dagger}$ \\
\hline & $\begin{array}{l}\text { Number of animals with cracks } \\
\text { and scabs on the skin }\end{array}$ & 0 & 0 & 0 & 2 & 2 \\
\hline & Irritation Index & 1.01 & 1.3 & 2.3 & 1.1 & 1.5 \\
\hline & Body weight (MN $\pm \mathrm{SD})$ & $2.30 \pm 0.15$ & & & & $2.87 \pm 0.183$ \\
\hline
\end{tabular}

(-) Slow hair growth, $(+)$ Normal hair growth, $(++)$ Quick hair growth.; ${ }^{*}$ Significantly different $\mathrm{P} \leq 0.05$, day 12 vs. day 1 (F $=$ $11,07143, \mathrm{P}=0,00765)$.; ${ }^{*}$ Significantly different $\mathrm{P} \leq 0.05$, day 19 vs. day $1(\mathrm{~F}=18,76623, \mathrm{P}=0,00148)$.; ${ }^{\dagger}$ Significantly different $\mathrm{P} \leq 0.05$, day 28 vs. day $1(\mathrm{~F}=21,31579, \mathrm{P}=9,55098 \mathrm{E}-4)$.

Table 6: Mean blood haematology values of rabbits treated topically in PLFO compared to control group.

\begin{tabular}{lll}
\hline Blood parameters & $\begin{array}{l}\text { Control } \\
\text { Median } \pm \text { IQR }(n=6)\end{array}$ & $\begin{array}{l}\text { PLFO }\left(1 \mathrm{ml} / \mathrm{Kg} \mathrm{BW} / \mathrm{site} \text { of } 6 \mathrm{~cm}^{2}\right) \\
\text { Median } \pm \mathrm{IQR}(n=6)\end{array}$ \\
\hline HT $(\%)$ & $36.3[29.12-42]$ & $40.5[28.2-45]$ \\
$\mathrm{RBC}\left(10^{6} / \mathrm{mm}^{3}\right)$ & $5.9[3.95-8.5]$ & $5.95[4.1-8.3]$ \\
$\mathrm{Hb}(\mathrm{g} / \mathrm{dL})$ & $12.3[9.9-14]$ & $12.55[9-16]$ \\
$\mathrm{MCV}\left(\mathrm{u}^{3}\right)$ & $55[47-59]$ & $54[48-70]$ \\
$\mathrm{MCHC}(\mathrm{g} / \mathrm{dL})$ & $34.3[32.5-36]$ & $33.5[31.9-36]$ \\
$\mathrm{WBC}\left(10^{3} / \mathrm{mm}^{3}\right)$ & $5200[3700-6700]$ & $5100[3900-10200]$ \\
$\mathrm{LY}\left(10^{3} / \mathrm{mm}^{3}\right)$ & $50.05[24.1-61.7]$ & $48.9[29.3-66.9]$ \\
MO $\left(10^{3} / \mathrm{mm}^{3}\right)$ & $8.05[5-11.6]$ & $6.6[2.7-24]$ \\
GR $\left(10^{3} / \mathrm{mm}^{3}\right)$ & $42.7[28.7-67]$ & $45.85[9-61.8]$ \\
PLT $\left(10^{3} / \mathrm{mm}^{3}\right)$ & $295[115-430]$ & $205[60-430]$ \\
\hline
\end{tabular}

- No significant difference between the two groups $(\mathrm{P}>0.05)$ for the various haematological parameters.

\section{Biochemical parameters}

Generally, the biochemical parameters of the two groups correspond to physiological norms cited by several authors for the rabbit species (Table 7). Statistical analysis by Mann-Whitney U test showed that no parameter had any significant difference between the two groups. Based on these results, we can confirm that topical application of PLFO, at a dose of $1 \mathrm{ml} / \mathrm{kg}$, did not involve any disturbance of biochemical parameters.

Table 7: Mean serum chemistry values in rabbits treated topically in PLFO and control group.

\begin{tabular}{lll}
\hline Blood parameters & $\begin{array}{l}\text { Control } \\
\text { Median } \pm \operatorname{IQR}(n=6)\end{array}$ & $\begin{array}{l}\text { PLFO }\left(1 \mathrm{ml} / \mathrm{Kg} \mathrm{BW} / \text { site of } 6 \mathrm{~cm}^{2}\right) \\
\text { Median } \pm \mathrm{IQR}(n=6)\end{array}$ \\
\hline AST $(\mathrm{U} / \mathrm{L})$ & $19.5[13-61]$ & $26[18-50]$ \\
ALT $(\mathrm{U} / \mathrm{L})$ & $49.5[30-61]$ & $39.5[25-62]$ \\
Alk-P $(\mathrm{U} / \mathrm{L})$ & $97.5[87-120]$ & $115[90-146]$ \\
CREA $(\mathrm{mg} / \mathrm{dL})$ & $9.75[9-12]$ & $10.8[9.7-12]$ \\
UREA $(\mathrm{g} / \mathrm{L})$ & $0.26[0.24-0.4]$ & $0.34[0.29-0.4]$ \\
GLUC $(\mathrm{mg} / \mathrm{dL})$ & $0.77[0.6-0.85]$ & $0.93[0.75-1.25]$ \\
TP $(\mathrm{g} / \mathrm{dL})$ & $61[49-70]$ & $62.5[55-72]$ \\
ALB $(\mathrm{g} / \mathrm{dL})$ & $16.5[15-18]$ & $19.5[14-33]$ \\
Cholesterol $(\mathrm{g} / \mathrm{L})$ & $0.45[0.4-0.8]$ & $0.37[0.17-0.8]$ \\
\hline
\end{tabular}




\begin{tabular}{lll}
\hline Triglycerides $(\mathrm{g} / \mathrm{L})$ & $0.6[0.55-0.8]$ & $0.57[0.5-0.9]$
\end{tabular}

- No significant differences between the two groups ( $\mathrm{P}>0.05)$.

. Pathological Anatomy and Histology

The general appearance of the organs of treated rabbits, and their relative weights were similar to those of control rabbits (Table 8). These organs were subjected to pathological and histological study, as some products may affect one or other of the functions of these organs. Atrophy or hypertrophies are the consequences of such alterations. In our study, the histological structure of the kidney (Figure 1) and liver (Figure 2) showed no abnormalities on microscopic examination of sections after preparation and staining with hematoxylin \& eosin. Histological examination, which focused on the skin of treated rabbits (Figure 3), showed an inflammatory reaction with a large inflammatory polymorphic granuloma, composed of poly nuclear cells, lymphocytes and plasmocytes. No abnormality of pilosebaceous annexes had been shown.

Table 8: Organ weights of rabbits treated with PLFO topically compared to the control group.

\begin{tabular}{lll}
\hline Organs & Control & PLFO $\left(1 \mathrm{ml} / \mathrm{Kg} \mathrm{BW} / \mathrm{site}\right.$ of $\left.6 \mathrm{~cm}^{2}\right)$ \\
& Mean $\pm \mathrm{SD}(n=6)$ & Mean $\pm \mathrm{SD}(n=6)$ \\
\hline Liver & $61.15 \pm 254.44$ & $58.35 \pm 152.77$ \\
Kidney (2) & $7.5 \pm 0.53$ & $8.13 \pm 0.66$ \\
Legs & $10.51 \pm 0.96$ & $7.31 \pm 0.19$ \\
Cerebrum & $5.71 \pm 0.26$ & $5.78 \pm 0.30$ \\
Cerebellum & $0.8 \pm 0.01$ & $1.00 \pm 0.12$ \\
Testis (2) & $3.61 \pm 0.84$ & $3.18 \pm 0.45$ \\
Heart & $3.63 \pm 0.09$ & $4.15 \pm 0.38$ \\
Adrenals (2) & $0.48 \pm 0.00$ & $0.54 \pm 0.00$ \\
Spleen & $0.66 \pm 0.04$ & $0.75 \pm 0.01$ \\
Full bladder & $6.96 \pm 1.94$ & $8.75 \pm 1.36$
\end{tabular}

- No significant difference between the two groups ( $\mathrm{P}>0.05)$ for the weights of individual organs.

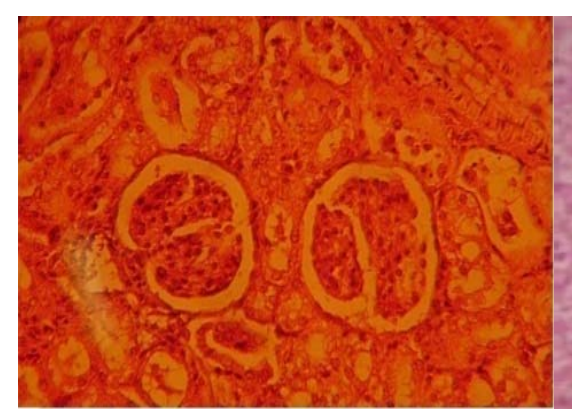

Fig 1: Histology of a kidney stained with $\mathrm{HE}$ in rabbits treated with $P$. lentiscus fatty oil.

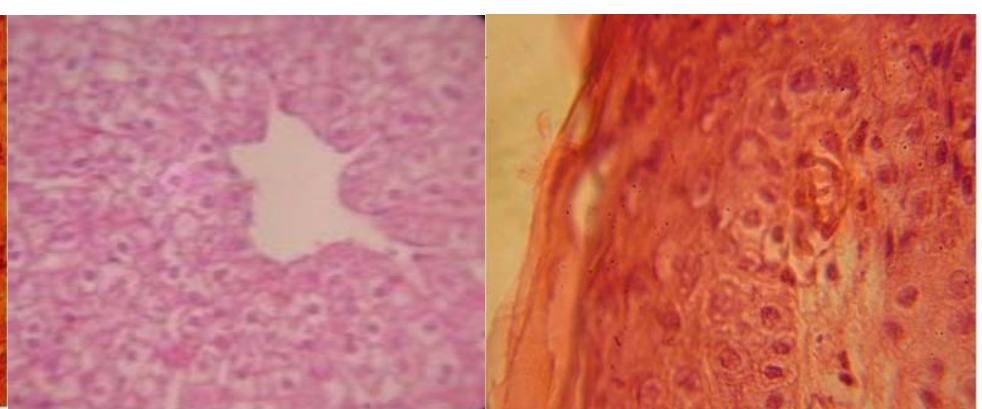

Fig 2: Liver histology stained with $\mathrm{HE}$ in rabbits treated with $P$. lentiscus fatty oil.
Fig 3: Histology of the skin stained with $\mathrm{HE}$ in rabbits treated with $P$. lentiscus fatty oil.

\section{Discussion}

The evaluation of the potential for eye and skin irritation is essential for ensuring the safety of individuals in contact with substances in cosmetics, industrial, and in pharmaceutical applications (Ngo and Maibach, 2010). The Draise rabbit eye and skin irritancy tests have been the standard for such ocular and dermal safety assessments for over 60 years (Ngo and Maibach, 2010).

In the present study, we investigated eye and skin irritation potential after a single application of PLFO and the sub acute dermal toxicity of this fatty oil. Based on current results, the tested oil may be considered as slightly irritant on the eye and the skin in case of single exposure, but repeated exposures for 28 days induced cumulative irritation reaction.

An irritant reaction is described as localized inflammation consecutively to dermal penetration of irritant agents. The primary cutaneous irritancy is known as toxic or irritant contact dermatitis (ICD). The ICD manifests a classic wounding response in the skin, with the formation of erythema, oedema, or both. The symptoms are due to dilatation of dermal blood vessels and transudation of fluid and inflammatory cells from the vascular space into the surrounding tissues (DeLeo et al., 1995). Other authors reported that the skin reactions may be attributed to the removal of surface lipids or water soluble substances and denaturation of scleroproteins of the horny layer leading to progressive skin irritation and damage (Okuda et al., 2002; Smeenk, 1969; Wadaan, 2006). The intensity of this inflammatory response is proportional to the exposure dose 
(Patil and Maibach, 1994). Duration of exposure, contact frequency, occlusion (Chew and Maibach, 2006), period and method of exposure (Mathias et al., 1978) are also important influences in the appearance of clinical symptoms.

The ICD and allergic contact dermatitis (ACD), both immune and non immune-based inflammatory processes may be involved. Immunologic-related toxicity is referred to as allergic dermatitis, while non immunologic inflammatory skin effects resulting from contact is referred to as primary irritation. Both of ICD and ACD have similar clinical characteristics including erythema, induration, scaling, and vesiculation on skin areas of direct contact to the chemical agent (Ngo and Maibach, 2010). Based on the differences between these two dermal reactions, we would ask if tested rabbits have developed an ACD following the dermal application of PLFO?

It is known that vegetable oils provide triglycerides and a broad spectrum of fascinating fatty acids like oleic, linoleic, linolenic, arachidonic, and erucic. Consequently, they have good compatibility with the natural sebum in the skin (Dweck, 2002). More attention has been focused on the role that essential fatty acids (EPA's) have in acting as precursors of a variety of inflammatory mediators (Wright, 1998). Initially, the cyclo-oxygenase and lipoxygenase products of arachidonic acid attracted most interest as mediators of inflammation, pain, and modulators of mononuclear cell behavior in inflammatory skin disease (Camp, 1982; Dowd and greaves, 1985). More recently, other 20 carbon fatty acids of both the n- 6 and n-3 series have been more fully investigated (Wright, 1998). According to Dweck (2002), $\gamma$ - linolenic acid (GLA) is a crucial part of the prostaglandin synthesis responsible for the inflammatory conditions of the skin.

Some researchers have reported some cases of allerginicity in humans due to olive oil (Isaksson and bruze, 1999), irritancy has also been discussed in connection with positive patch tests to olive oil (Kränke et al., 1997). According to Isaksson and Bruze (1999), several of the 20 cases reported in the literature with a positive patch test to olive oil had been patch tested with the 9 known components of olive oil, without any positive reactions, they did not elucidate any special component in the olive oil as being the cause of this patient's eczema. An extensive histopathological study on 18 potential penetration enhancers revealed that $10 \%$ oleic acid as an aqueous dispersion induced a significant change in nude mice skin tissue, indicating a possible skin irritation effect (Lashmar et al., 1989). Sintov et al. (1998) have provided further supporting evidence, that although effective, oleic acid induces some inflammatory effect on the skin in a dose dependent manner.

In view of these previous studies, the dermal reactions observed following application of PLFO may be attributed to the tested dose $(1 \mathrm{ml} / \mathrm{kg} \mathrm{BW} /$ site of $6 \mathrm{Cm} 2)$. The doses used ordinarily in traditional medicine were lower. In addition, this result cannot be directly extrapolated to humans, since the rabbit is typically more responsive than man; its skin is more permeable than human skin (Bronaugh et al., 1989). We would now be asking if one or more component of PLFO may be implicated in these dermal reactions. We hypothesize also possible allergic response since some rabbits have manifested more reactions than others and since authors have reported allergic contact dermatitis with other vegetable oils. Some studies are necessary to give more details of this edible oil which know an increasing production and use for therapeutic purposes.

\section{Conclusion}

Results from this study demonstrated that the vegetable oil extracted from the fruits of Pistacia lentiscus is slightly irritating to the skin and the eye of rabbits after a single application. But when applied topically at the dose of $1 \mathrm{ml} / \mathrm{kg} \mathrm{BW}$ for 28 consecutive days, the oil caused a reversible irritant contact dermatitis with skin thickening from the end of the second week until the end of the experiment.

\section{Acknowledgements}

The authors thank Dr. B. Boutobza, Dr. N. Kouider and M. Zaïer for their collaboration and skilful help to accomplish this work.

\section{References}

1. Al-Habbal, M.J., Al-Habbal, Z. and Huwez, F.U. (1984). A double-blind controlled clinical trial of mastic and placebo in the treatment of duodenal ulcer, J. Clin. Exp. Pharmacol. Physiol. 11: 19-23.

2. Amhamdi Hassan, Fatima Aouinti, Jean Paul Wathelet and Ali Elbachiri (2009). Chemical Composition of the Essential Oil of Pistacia lentiscus L. from Eastern Morocco. Rec. Nat. Prod. 3 (2) : 90 - 95.

3. Barra A., V. Coroneo, S. Dessi, P. Cabras, A. Angioni (2007). Characterization of the volatile constituents in the essential oil of Pistacia lentiscus L. from different origins and its antifungal and antioxidant activity. J. Agric. Food Chem. 55 : 7093 - 7098.

4. Benhammou, N., Atik Bekkara, F. and Panovska, T.K. (2008). Antioxidant and antimicrobial activities of the Pistacia lentiscus and atlantica extracts. Afr. J. Pharm. Pharm. 2(2) : 22-28.

5. Bentley R.Y. and Trimen H. (1980). Medicinal plants. In Gardeli et al. (Eds) Essential oil composition of Pistacia lentiscus L. and Myrtus communis L.: Evaluation of antioxidant capacity of methanolic extracts. Food Chem. 1-11.

6. Benyoucef, E., Charchari, S., Nacer-Bey, Yahiaoui, N., Chakou, A. and Bellatreche, M. (2005). The essential oil of Pistacia Lentiscus L. from Algeria. J. Essent. Oil Res. 17 : 642-644.

7. Bonnier, G., Douin, R. (1990). La Grande Flore. Belin, Paris.

8. Bronaugh, R. L., Stewart, R. F., Storm, J. E. (1989). Extent of cutaneous metabolism during percutaneous absorption of xenobiotics. Toxicol. Appl. Pharmacol. 99 : 534-543.

9. Calabro G. and P. Curro (1974). Costituenti degli oli essenziali Nota IV. Essenza di lentisco. Essence Deriv. Agrum. 44 : 82-92. 
10. Camp, R. D. R. (1982). Prostaglandins, Hydroxy fatty acids, leukotrienes and inflammation of the skin. Clinical and Experimental Dermatology, $7: 435-444$

11. Castola V., A. Bighelli and J. Casanova (2000). Intraspecic chemical variability of the essential oil of Pistacia lentiscus L. from Corsica. Biochemical Systematics and Ecology. 28 : 79-88.

12. Charef, M., Yousfi, M., Saidi, M. and Stoccker, P. (2008). Determination of the fatty acid composition of Acorn (Quercus), Pistacia lentiscus seeds growing in Algeria. J Am Oil Chem Soc. 85 : 921-924.

13. Chew A. and Maibach H.I., eds. (2006). Irritant Dermatitis. Germany: Springer.

14. Dabos K.J., E.Sfika,L.J.Vlatta,G. Giannikopoulos (2010). The effect of mastic gum on Helicobacter pylori: A randomized pilot study. Phytomedicine, $17: 296-299$.

15. Dedoussis, G.V.Z., Kaliora, A.C., Psarras, S., Chiou, A., Mylona, A., Papadopoulos, N.G. and Andrikopoulos, NK. (2004). Antiatherogenic effect of Pistacia lentiscus via GSH restoration and down regulation of CD36 mRNA expression. Atherosclerosis, $174: 293-303$.

16. DeLeo, V. A., Carver, M. P., Hong, J., Fung, K., Kong, B., DeSalva, S. (1995). Arachidonic acid release: an in vitro alternative for dermal irritancy testing. Food and Chemical toxicology, 34 (2) : $167-176$.

17. Djerrou, Z., Maamari, Z., Hamdi-Pacha, Y., Serakta, M., Riachi, F., Djaalab, H. and Boukeloua, A. (2010). Effect of virgin fatty oil of Pistacia lentiscus on experimantal burn wound's healing in rabbits. Afr. J. Trad. CAM. 7(3) : 258-263.

18. Djerrou Z., Y. Hamdi-Pacha, A.M. Belkhiri, H. Djaalab, F. Riachi, M. Serakta, A. Boukeloua, Z. Maameri (2011). Evaluation of Pistacia Lentiscus Fatty Oil Effects on Glycemic Index, Liver Functions and Kidney Functions of New Zealand Rabbits. Afr J Tradit Complement Altern Med. 8(S) : 214-219.

19. Dowd, P. M., Greaves, M. W. (1985). Cutaneous responses to lipoxygenase products of arachidonic acid. Acta Dermatologica et Veneorologica (Stokholm) Suppl. $120: 18-22$.

20. Draize, J., Woodard, G. and Calevery, H. (1944). Methods for the study of irritation and toxicity of substances applied topically to the skin and mucous membranes. Journal of pharmacology and Experimental therapeutics, $82: 377-390$

21. Duru, M.E., Cakir, A., Kordali, S., Zengin, H., Harmandar, M., Izumi, S. and Hirata, T. (2003). Chemical composition and antifungal properties of essential oils of three Pistacia species. Fitoterapia. $74: 170$-176.

22. Dweck, A.C. (2002). Herbal medicine for the skin. Their chemistry and effects on skin and mucous membranes. Personal Care Magazine, 3(2) : 19 - 21.

23. EPA (1998). Health Effects Test Guidelines. OPPTS 870.3200, 21/28-Day Dermal Toxicity.

24. Fernandez A., A. Camacho, C. Fernandez, P. Perez and J. Altarejos (2000). Composition of the essentialoils from galls and aerial parts of Pistacia lentiscus L. J. Essent. Oil Res., 12: 19-23.

25. Isaksson Marlène and Bruze Magnus (1999). Occupational allergic contact dermatitis from olive oil in a masseur. J Am Acad Dermatol., 40 : 312-316.

26. Kay, J. H. and Calandra, J. C. (1962). Interpretation of eye irritation tests. Journal of the Society of Cosmetic Chemists, $13: 281-289$.

27. Kivçak B., S. Akay, B. Demirci, K.H.C. Baser (2004). Chemical Composition of Essential Oils from Leaves and Twigs of Pistacia lentiscus var. chia and Pistacia terebinthus from Turkey. Pharm. Biol., 42 : 360-366.

28. Kordali, S., Cakir, A., Zengin, H. and Duru, M.E. (2003). Antifungal activities of the leaves of three Pistacia species growth in Turkey. Fitoterapia, $74:$ 164-167.

29. Kränke B, Komericki P, Aberer W. (1997). Olive oil--contact sensitizer or irritant? Contact Dermatitis, 36(1) : 5-10.

30. Lansdown, A.B.G. (1972). An appraisal of methods for detecting primary skin irritants. J. Soc. Cosmet. Chem. $23: 739-772$.

31. Lashmar, U. T., Hadgraft, J., Thomas, N. (1989). Topical application of penetration enhancers to the skin of nude mice: a histological study. J. Pharm. Pharmacol. 41 : $118-121$.

32. Le Floc'h, E., \& Nabli, M.A. (1983). Programme flore et végétation Tunisiennes. In: Contribution à une étude ethnobotanique de la flore Tunisienne. Tunis. Ministère de l'enseignement supérieur et de la recherche scientifique, imprimerie officielle de la république Tunisienne, 144-145.

33. Margaris, N.S. (1981). Adaptative strategies in plants dominating Mediterranean type ecosystems. In: di Castri, R., Goodall, D.W., Specht, R.I. (Eds.), Ecosystems of the World. Mediterranean type Shrublands, Elsevier Science, 309-315.

34. Mathias CG, Maibach HI, Epstein J. (1978). Allergic contact photodermatitis to paraaminobenzoic acid. Arch Dermatol, $114: 1665-1666$.

35. Mecherara-Idjeri S., A. Hassani, V. Castola, J. Casanova (2008). Composition and chemical variability of the essential oil from Pistacia lentiscus L. growing wild in Algeria Part 1 : Leaf oil. J. Essent. oil Res. 20 : 32-38.

36. MHLW (Ministry of Health, Labour and Welfare), Japan (2002). Toxicity Testing Reports of Environmental Chemicals, 9: 233-254.

37. Ngo, M. A. and Maibach, H. I. (2010). Dermatotoxicology: historical perspective and advances. Toxicol. Appl. Pharmacol. $243: 225-238$.

38. OECD (1981). Toxicité cutanée à doses répétées : Etude à $21 / 28$ jours. Ligne directrice 410 pour l'évaluation des produits chimiques.

39. OECD (2002). Acute dermal irritation /corrosion. Method 404. OECD Guidelines for testing of chemicals.

40. OECD (2002). Acute eye irritation/corrosion. Method 405. OECD Guidelines for testing of chemicals.

41. Okuda, M., Yoshiike, T. and Ogawa, H. (2002). Detergent-induced epidermal barrier dysfunction and its prevention. J. Dermatol. Sci. 30 : 173 - 179. 
42. Palevitch D, Yaniv Z (2000). Medicinal Plants of the Holy Land. Modan Publishing House, Tel Aviv, Israel. In Ljubuncic et al. (eds) The effects of aqueous extracts prepared from the leaves of Pistacia lentiscus in experimental liver disease. J. Ethnopharmacol, 198 - 204.

43. Patil S, Maibach H.I. (1994). Effect of age and sex on the elicitation of irritant contact dermatitis. Contact Dermatitis, $30: 257-264$.

44. Pellecuer, J., Jacob, M., Simeon, D.M., Dusart, G., Attisto, M., Barthez, M., Gourgas, L., Pascal, B. and Tomei, R. (1980). Essais d'utilisations d'huiles essentielles de plantes aromatiques Méditerranéennes en odentologie conservatrice. Plant Médicin Phytothér, 14 : 83 - 98.

45. Serpico, M., and White, R. (1998). Chemical analysis of coniferous resins from ancient Egypt using gas chromatography/mass spectrometry (GC/MS), in Proceedings of the Seventh International Congress of Egyptologists, Cambridge, 3-9 September 1995, Orientalia Lovaniensia Analecta, (Peeters: Leuven), 82 : 1039 1048.

46. Sintov Amnon, Ze'evi Amira, Uza Rina, Nyska Abraham (1999). Influence of pharmaceutical gel vehicles containing oleic acid/ sodium oleate combinations on hairless mouse skin, a histological evaluation. European Journal of Pharmaceutics and biopharmaceutics, $47: 299-303$

47. Smeenk, G. (1969). The influence of detergents on the skin (a clinical and biochemical study). Arch. Clin. Exptl. Dermatol. $235: 180$ - 185.

48. Takahashi, T., Yokoo, Y., Inoue, T. and Ishil, A. (1999). Toxicological studies on Procyanidin B-2 for external application as a hair growing agent. Food and Chemical Toxicology, 37 : 545 - 552.

49. Tingshuang, Y. I., Jun, W., Avi, G. G., \& Dan, E. P. (2008). Phylogenetics and reticulate evolution in Pistacia (Anacardiaceae). American Journal of Botany, 95 : 241-251.

50. Tounes, M., Abdennour, C. and Houaine, N. (2008). Influence of Pistacia lentiscus oil on serum biochemical parameters of domestic rabbits Oryctolagus cuniculus in mercury induced toxicity. European Journal of Scientific Research, 24 (4) : 591 - 600.

51. Trabelsi Hajer, Olfa Aicha Cherif, Faouzi Sakouhi, Pierre Villeneuve, Justin Renaud, Nathalie Barouh, Sadok Boukhchina, Paul Mayer (2012). Total lipid content, fatty acids and 4-desmethylsterols accumulation in developing fruit of Pistacia lentiscus L. growing wild in Tunisia. Food Chemistry, 131 : 434-440.

52. Ucciani, E. (1995). Nouveau dictionnaire des huiles végétales- Composition en acides gras. Techniques et documentation. Lavoisier, Paris.

53. Vidrich, V., Fusi, P., Graziano, A., Silvestrini, E., Michelozzi, M. and Marco, F. (2004). Chemical composition of the essential oil of Pistacia Lentiscus L. J. Essent. Oil Res. 16 : 223-226.

54. Wadaan Mohammad A. M. (2006). Toxicological evaluation of of synthetic detergent-induced effects in rat skin. J. King Saud Univ., 19, Science (1) : 1-8.

55. Wright, S. (1989). Essential fatty acids and the skin. Prostaglandins, Lentrienes and Fatty acids: Reviews, 38: 229 236.

56. Zhu, J.J., Zeng, X.-P., Berkebile, D., Du, H.-J., Tong, Y. and Qian, K. (2009). Efficacy and safety of catnip (Nepeta Cataria) as a novel filth fly repellent. Medical and Veterinary Entomology, $23: 209-216$.

57. Zrira, S., Elamrani, A. and Benjilali, B. (2003). Chemical composition of the essential oil of Pistacia lentiscus L. from Morocco- a seasonal variation. Flavour Fragr. J., 18 : 475-480. 